\title{
Prevalence and Determinants of Communicable and Non-Communicable Diseases in India
}

\author{
Pugalenthi ${ }^{1}$ and Ndanyuzwe Aime ${ }^{2}$ \\ ${ }^{1}$ Assistant Professor, ${ }^{2}$ Research Scholar \\ ${ }^{1 \& 2}$ Department of Population Studies, Annamalai University, Tamil Nadu, India \\ E-Mail: pugalvelu@gmail.com,ndanyuzwsebakara@gmail.com
}

\begin{abstract}
The parts and organs communicate with each other to ensure function of the body properly. Communication among various regions of the body is essential for enabling the organism to respond appropriately to find any changes in the internal and external environments. Communicable and noncommunicable disorders are often quite complex involving a mixed picture of hypo secretion and hyper secretion. The objectives are to study the regional variations of communicable and non-communicable diseases among the currently married women; to examine the communicable and non-communicable diseases and the various socio-economic and demographic characteristics and to study predictors of communicable and non-communicable diseases with Principal component analysis (PCA).The present study is being made to analyze from National Family Health Survey (NFHS- III) conducted during 2005-06. Total number of sample was 4102 from the collected sample sizes and particularly those who were answered for the above questions were taken for the analysis to find accurate information. To find the predictors of Diabetics, Asthma and Thyroid, Principle Component Analysis (PCA) was used. The analysis part represents that of the communicable and noncommunicable diseases like Asthma was experienced by those who do not use LPG/Electricity. It was about 62 percent of respondents were experienced Asthma than the other two diseases (Thyroid and Diabetics). But those diseases were in higher proportion among those who had the level of education was secondary and higher secondary. It indicates that of the communicable and non-communicable diseases Asthma was experienced by 48.6 percent compared to the other two diseases such as Thyroid and diabetics among the respondents. Keywords: NFHS, Diseases. Asthma, Diabetics, Thyroid, PCA
\end{abstract}

\section{INTRODUCTION}

The parts and organs communicate with each other to ensure function of the body properly. Communication among various regions of the body is essential for enabling the organism to respond appropriately to find any changes in the internal and external environments. Communicable and non-communicable disorders are often quite complex involving a mixed picture of hypo secretion and hyper secretion. Further, Premature deaths from NCDs are largely preventable, and many are mainly driven by four big risk factors: physical inactivity, unhealthy diets, tobacco use, and the harmful use of alcohol. In India, the communicable and non-communicable diseases are common which includes Diabetics, Asthma and Thyroid related disorders.
The communicable and non-communicable diseases may lead to fatigue, dyspnea, and weight gain, palpitations associated with anemia, cold intolerance and tiredness. Noncommunicable diseases (NCDs) are defined as diseases of long duration, and are generally slow in progression. NCDs are replacing communicable diseases, maternal and child health as well as malnutrition as the leading cause of death. In India, with a population of 1.21 billion, an estimated 108 million people suffer from communicable and noncommunicable and metabolic disorders. Of these 108 million, 42 million suffer from thyroid disorders. (Kochupillai, 2000, p.1064).

Some diseases marked by high levels of blood glucose resulting from defects in insulin production, insulin action, diabetes can lead to serious complications and premature death. The disease can cause long-term complications including kidney problems, nerve damage, blindness, and early coronary heart disease and stroke. To control their blood sugar levels and reduce the risk of developing diabetes complications, children with this condition need regular injections of insulin. NCDs are the leading cause of death in the world; responsible for 63 percent deaths worldwide in 2008. The majority of these deaths (36 million) were attributed to cardiovascular diseases (48 percent), cancers (21percent), chronic respiratory diseases (12 percent) and diabetes ( 3 percent). (Kalpa Sharma et al., 2013, p.9).

People with diabetes can take steps to control the disease and lower the risk of complications. Diabetes and its complications have a significant economic impact on individuals, families, health systems and countries. Data collected in the Survey indicated that the proportion of women in the Chattisgharh region who were undernourished was 43 percent. This compared with 46 percent in Bihar, 42 percent in Madhya Pradesh, and 41 percent in Orissa.( Lincy et al., 2011, p.1).

A study of 800 children in India referred for thyroid problems, investigators determined the percentages of the children whose laboratory tests determined their thyroid status: 79 percent were hypothyroid, 19 percent were euthyroid, and 2 percent were hyperthyroid. (Meena, P, 1997, p.14). 
The other health problems experienced during rainy season include asthma, arthritis, skin diseases, cold (cough, sneeze, and phlegm), etc. The season of rains is here again and we are all set to enjoy it to the hilt irrespective of our age, while watching the lovely weather from the comfort of their homes. But there are people who want to go out and enjoy the season dancing in the rain. In order to keep ourselves safe, we need to know the most common diseases that to stay away from and their remedies, in case fall prey. Airborne bacteria can be toxic, allergenic, and/or infectious. Bacteria, fungi, viruses, protozoa's, and microscopic animals have been linked to poor indoor air quality (Fabian et al., 2005, p.768). Exposure to the microbial fragments and metabolites may result in adverse health effects. Elevated concentrations of bacteria are associated with an increasing probability of epidemics and food pollution and may be responsible for a number of respiratory and dermatological infections and diseases (Aydogdu et al., 2008, p.79).

With this back ground this paper is being made an attempt to study the prevailing of communicable and noncommunicable diseases in India and to some extent to find the factor affecting those diseases.

\section{OBJECTIVES OF THE STUDY}

1. To study the regional variations of communicable and non-communicable diseases among the currently married women

2. To examine the socio-economic and demographic characteristics of the respondents

3. To study predictors of communicable and noncommunicable diseases using Principal component analysis (PCA)

\section{MATERIALS AND METHODS}

The present study is being made to analyze from National Family Health Survey (NFHS- III) conducted during 200506. The survey provides information on Asthma, Diabetics and Thyroid as
a. Do you have Diabetics?
b. Do you have Asthma? and
c. Do you have Thyroid?

Those are taken for the analysis. Total number of sample was 4102 from the collected sample sizes and particularly those who were answered for the above questions were taken for the analysis to find accurate information. To find the predictors of Diabetics, Asthma and Thyroid, Principle Component Analysis (PCA) was used.

The variables such as socio-economic variables; level of education, wealth index, type of fuel used, drinking water, type of toilet, toilet shared and place of birth, living condition: type of floor, wall and roof, Knowledge; news reading, listening radio and watching television, Demographic variables; age group, religion, currently pregnancy and total children ever born partner's age which are assumed to be the vital factor in determining the communicable and non-communicable diseases of the respondents chosen for the analysis. Factor analysis was purposively used for the present data composition and accordingly matrixes of $4102 \times 23$ were subjected to dimension reduction process. 8 out of 23 variables were extracted for the elucidation purpose of present study. So the data were reduced to $23 \times 23$ inter correlation matrix to facilitate for easy interpretation. In addition to the above, the factor loading matrix was used to explain the strength of relationship and the variance of each variable with all other variables.

\section{ANALYSIS AND FINDINGS}

TABLE I DISTRIBUTION OF RESPONDENTS BY COMMUNICABLE AND NON-COMMUNICABLE DISEASES

\begin{tabular}{|c|c|c|c|c|}
\hline \multirow{2}{*}{ States } & \multicolumn{3}{|c|}{$\begin{array}{l}\text { Communicable And Non- } \\
\text { Communicable Diseases }\end{array}$} & \multirow[b]{2}{*}{ Total } \\
\hline & Diabetics & Asthma & Thyroid & \\
\hline $\begin{array}{l}\text { Jammu and } \\
\text { Kashmir }\end{array}$ & $17(1.6)$ & $28(1.5)$ & $7(0.6)$ & 52 \\
\hline $\begin{array}{l}\text { Himachal } \\
\text { Pradesh }\end{array}$ & $26(2.3)$ & $6(0.3)$ & $17(1.5)$ & 49 \\
\hline Punjab & $28(2.5)$ & $33(1.8)$ & 21(1.8) & 82 \\
\hline Uttaranchal & $24(2.2)$ & $15(0.8)$ & $8(0.7)$ & 47 \\
\hline Haryana & $28(2.5)$ & $40(2.2)$ & $9(0.8)$ & 77 \\
\hline Delhi & $50(4.5)$ & $17(0.9)$ & $41(3.6)$ & 108 \\
\hline Rajasthan & $11(1.0)$ & $62(3.4)$ & $16(1.4)$ & 89 \\
\hline Uttar Pradesh & $57(5.1)$ & $115(6.2)$ & $59(5.2)$ & 231 \\
\hline Bihar & $40(3.6)$ & $54(2.9)$ & $25(2.2)$ & 119 \\
\hline Sikkim & $22(2.0)$ & $82(4.4)$ & $21(1.8)$ & 125 \\
\hline $\begin{array}{l}\text { Arunachal } \\
\text { Pradesh }\end{array}$ & $8(0.7)$ & $26(1.4)$ & $27(2.4)$ & 61 \\
\hline Nagaland & $19(1.7)$ & $44(2.4)$ & $15(1.3)$ & 78 \\
\hline Manipur & $34(3.1)$ & $47(2.5)$ & $103(9.0)$ & 184 \\
\hline Mizoram & $6(0.5)$ & $48(2.6)$ & $17(1.5)$ & 71 \\
\hline Tripura & $24(2.2)$ & $99(5.4)$ & $35(3.1)$ & 158 \\
\hline Meghalaya & $10(0.9)$ & 19(1.0) & $5(0.4)$ & 34 \\
\hline Assam & $14(1.3)$ & $51(2.8)$ & $25(2.2)$ & 90 \\
\hline West Bengal & $100(9.0)$ & $189(10.2)$ & 134(11.7) & 423 \\
\hline Jharkhand & $22(2.0)$ & $37(2.0)$ & $23(2.0)$ & 82 \\
\hline Orissa & $25(2.3)$ & $111(6.0)$ & $14(1.2)$ & 150 \\
\hline Chhattisgarh & $20(1.8)$ & 21(1.1) & $20(1.7)$ & 61 \\
\hline $\begin{array}{l}\text { Madhya } \\
\text { Pradesh }\end{array}$ & $45(4.1)$ & $71(3.8)$ & $29(2.5)$ & 145 \\
\hline Gujarat & $29(2.6)$ & $51(2.8)$ & $16(1.4)$ & 96 \\
\hline Maharashtra & $60(5.4)$ & $167(9.0)$ & $46(4.0)$ & 273 \\
\hline $\begin{array}{l}\text { Andhra } \\
\text { Pradesh }\end{array}$ & $90(8.1)$ & $117(6.3)$ & $72(6.3)$ & 279 \\
\hline Karnataka & $31(2.8)$ & $65(3.5)$ & $35(3.1)$ & 131 \\
\hline Goa & $57(5.1)$ & $55(3.0)$ & 19(1.7) & 131 \\
\hline Kerala & $73(6.6)$ & 123(6.7) & $181(15.8)$ & 377 \\
\hline Tamil Nadu & $13(12.5)$ & $56(3.0)$ & $104(9.1)$ & 299 \\
\hline Total & 1109 & 1849 & 1144 & 4102 \\
\hline
\end{tabular}


The above table reveals that the prevalence of communicable and non-communicable diseases in India, the highest proportion of diabetic cases was identified Tamil Nadu followed by West Bengal and Andhra Pradesh with the percentages of $12.5,9.0$ and 8.1 respectively. In contrast, the lowest proportions of the diabetic cases were identified in Meghalaya, Arunachal Pradesh and Mizoram with the percentages of $0.9,0.7$ and 0.5 respectively.

Similarly, the highest proportion of Asthma cases were identified in west Bengal, Maharashtra and Kerala with the percentages of $10.2,9.0$ and 6.7 respectively. In contrast, the lowest proportions of the diabetic cases were identified in Delhi, Uttaranchal, and Himachal Pradesh, with the percentages of 0.90 .8 and 0.3 respectively.

The highest proportions of Thyroid cases were reported in West Bengal and Tamil Nadu with the percentages of 15.8, 11.7 and 9.1 respectively. In contrast, the lowest proportions of the diabetic cases were identified in Haryana, Uttaranchal and Jammu and Kashmir, with the percentages of 0.80 .7 and 0.6 respectively. The analysis indicates that the socio economic and demographic characteristics may likely to influence on this diseases.

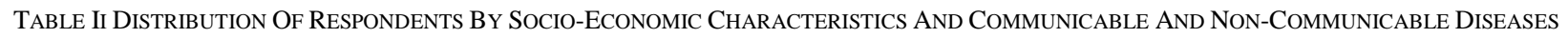

\begin{tabular}{|c|c|c|c|c|}
\hline \multirow{2}{*}{ Socio- Economic Characteristics } & \multicolumn{3}{|c|}{ Communicable And Non-Communicable Diseases } & \multirow{2}{*}{ Total } \\
\hline & Diabetics & Asthma & Thyroid & \\
\hline \multicolumn{5}{|c|}{ Religion } \\
\hline Hindus & $787(71.0)$ & $1290(69.8)$ & $804(70.3)$ & 2881 \\
\hline Muslims & $181(16.3)$ & $261(14.1)$ & $155(13.5)$ & 597 \\
\hline Christians & $88(7.9)$ & $199(10.8)$ & $122(10.7)$ & 409 \\
\hline Others & $53(4.8)$ & $99(5.4)$ & $63(5.5)$ & 215 \\
\hline \multicolumn{5}{|c|}{ Level of Education } \\
\hline No education & $285(25.7)$ & $681(36.8)$ & $209(18.3)$ & 1175 \\
\hline Primary & $190(17.1)$ & $329(17.8)$ & $151(13.2)$ & 670 \\
\hline Secondary & $504(45.4)$ & $676(36.6)$ & $543(47.5)$ & 1723 \\
\hline Higher & $130(11.7)$ & $163(8.8)$ & $241(21.1)$ & 534 \\
\hline \multicolumn{5}{|c|}{ Wealth index } \\
\hline Poorest & $33(3.0)$ & $226(12.2)$ & $60(5.2)$ & 319 \\
\hline Poorer & $82(7.4)$ & $279(15.1)$ & $89(7.8)$ & 450 \\
\hline Middle & $116(10.5)$ & $359(19.4)$ & $171(14.9)$ & 646 \\
\hline Richer & $287(25.9)$ & $437(23.6)$ & $278(24.3)$ & 1002 \\
\hline Richest & $591(53.3)$ & $548(29.6)$ & $546(47.7)$ & 1685 \\
\hline Not dejure resident & $24(2.5)$ & $78(6.2)$ & $37(3.8)$ & 139 \\
\hline \multicolumn{5}{|c|}{ Place of residence } \\
\hline Urban & $815(44.1)$ & $742(66.9)$ & $651(56.9)$ & 2208 \\
\hline Rural & $1034(55.9)$ & $367(33.1)$ & $493(43.1)$ & 1894 \\
\hline
\end{tabular}

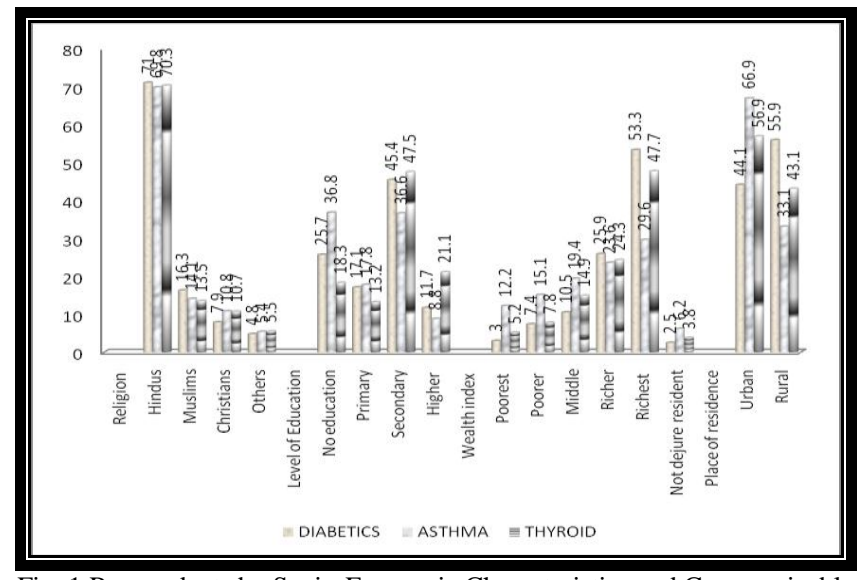

Fig. 1 Respondents by Socio-Economic Characteristics and Communicable and Non-Communicable Diseases
Fig. 1 shows the socio-economic characteristics of the respondents and communicable and non-communicable diseases. Religion of the respondents as concern the higher proportion all the three diseases were found to be high among the respondents of Hindus (71.0 Percent) followed by Muslims (69.8 percent) and Christians (70.3 percent).

Those who do have no education Asthma was the common diseases compared to other two diseases. Diabetics and Thyroid diseases were in higher proportion among those respondents who had the level of education was secondary and higher secondary.

The wealth index and communicable and noncommunicable diseases show that when wealth status 
increased, the proportion of diabetics increased 53 percent, followed by Thyroid and Asthma. Asthma account higher percentages among respondents who had wealth index below middle category. Those who were residing in urban area, Asthma and Thyroid were found to be higher proportion 66.9 and 56.9 percent respectively. The existing higher percentages of Asthma and Thyroid in urban areas may be due to the environmental pollution caused by human beings and availability and utilization of the safe drinking water.

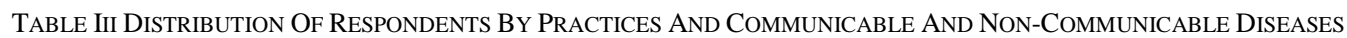

\begin{tabular}{|c|c|c|c|c|}
\hline \multirow{2}{*}{ Practices } & \multicolumn{2}{|c|}{ Communicable And Non-Communicable Diseases } & \multirow{2}{*}{ Total } \\
\cline { 2 - 4 } & Diabetics & Asthma & Thyroid & \\
\hline \multicolumn{5}{|c|}{ Type of fuel used } \\
\hline LPG/ Electricity & $621(56.0)$ & $616(33.3)$ & $574(50.2)$ & 1811 \\
\hline All other & $464(41.8)$ & $1154(62.4)$ & $533(46.6)$ & 2151 \\
\hline Not cooked in HH & $24(2.2)$ & $79(4.3)$ & $37(3.2)$ & 140 \\
\hline Drinking water & & & & \\
\hline protected & $191(17.2)$ & $359(19.4)$ & $211(18.4)$ & 1131 \\
\hline Unprotected & $918(82.8)$ & $1490(80.6)$ & $933(81.6)$ & 1356 \\
\hline
\end{tabular}

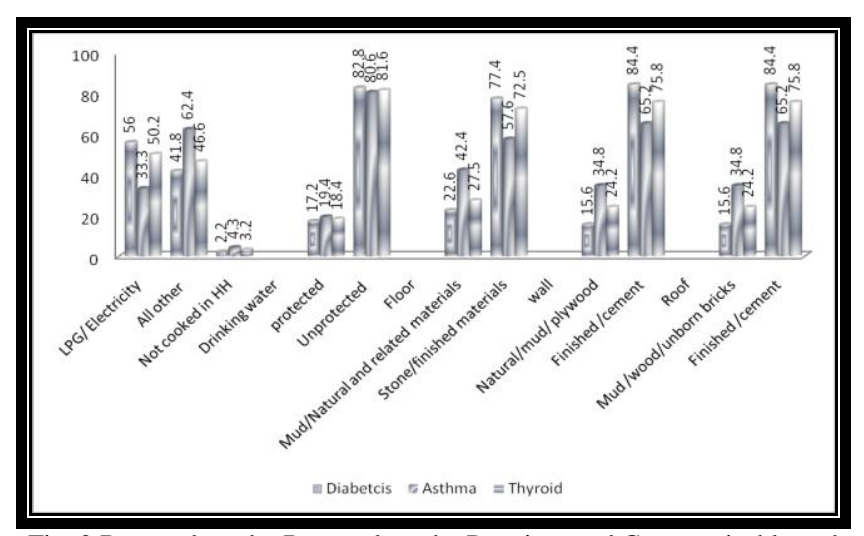

Fig. 2 Respondents by Respondents by Practices and Communicable and Non-Communicable Diseases
The Fig. 2 depicts the practices of the respondents and communicable and non-communicable diseases in the study areas. About 62 percentages of respondents were experienced Asthma among the respondents those who use other than LPG/Electricity.

The data analysis clearly indicates that the relationship of protected and unprotected water with the diseases. The respondents those who use unprotected water more than 80 percent of them experienced all the three types of diseases. But those who consume, the protected water the percentage of communicable and non-communicable diseases were very low.

TABle Iv Distribution Of Respondents By Living Condition And CommunicABle AND Non-Communicable Diseases

\begin{tabular}{|l|c|c|c|c|}
\hline \multirow{2}{*}{ Living Condition } & \multicolumn{1}{|c|}{ Communicable And Non-Communicable Diseases } & \multirow{2}{*}{ Total } \\
\cline { 2 - 5 } & Diabetics & Asthma & Thyroid & \\
\hline \multicolumn{5}{|c|}{ Floor } \\
\hline Mud/Natural and related materials & $251(22.6)$ & $784(42.4)$ & $315(27.5)$ & 1350 \\
\hline Stone/finished materials & $858(77.4)$ & $1065(57.6)$ & $829(72.5)$ & 2752 \\
\hline \multicolumn{5}{|c|}{ Wall } \\
\hline Natural/mud/ plywood & $173(15.6)$ & $644(34.8)$ & $277(24.2)$ & 1094 \\
\hline Finished /cement & $936(84.4)$ & $1205(65.2)$ & $867(75.8)$ & 3008 \\
\hline \multicolumn{7}{|c|}{ Roof } \\
\hline Mud /wood/unborn bricks & $173(15.6)$ & $644(34.8)$ & $277(24.2)$ & 1094 \\
\hline Finished /cement & $936(84.4)$ & $1205(65.2)$ & $867(758)$ & 3008 \\
\hline
\end{tabular}

Table IV explains living condition with the communicable and non-communicable diseases. Respondents those who live in Mud/ Natural and related materials, Natural/ Mud Plywood wall, Mud/ wood/ unborn bricks roof they were experienced Asthma than the other diseases such as Thyroid and Diabetics. It was observed from the analysis that those who live in stone/ finished materials, finished/ cement walls, and finished / cement roof they were experienced Diabetic. The above statement clearly indicates that economic status may likely to influence on the diseases of the respondents. As the economic status improve the living condition and life style of the respondents may change and this may lead to variation of diseases among the respondents. 
TABLE V Distribution OF RESPONDENTS By KNOWLEDGE AND COMMUNICABLE AND NON-COMMUNICABLE DISEASES

\begin{tabular}{|c|c|c|c|c|}
\hline \multirow{2}{*}{ Knowledge } & \multicolumn{3}{|c|}{ Communicable And Non-Communicable Diseases } & \multirow{2}{*}{ Total } \\
\hline & Diabetics & Asthma & Thyroid & \\
\hline \multicolumn{5}{|c|}{ News reading } \\
\hline Not at all & $538(48.6)$ & 1093(59.1) & $400(35.0)$ & 2031 \\
\hline Less than once in a week & $153(13.8)$ & $266(14.4)$ & 211(18.4) & 630 \\
\hline At least once in a week & $145(13.1)$ & 191(10.3) & $185(16.2)$ & 521 \\
\hline Almost everyday & $272(24.5)$ & $299(16.2)$ & $348(30.4)$ & 919 \\
\hline \multicolumn{5}{|c|}{ Listening to Radio } \\
\hline Not at all & $548(49.5)$ & $1000(54.1)$ & $490(42.8)$ & 2038 \\
\hline Less than once in a week & $182(16.4)$ & $293(15.8)$ & 193(16.9) & 668 \\
\hline At least once in a week & $114(10.3)$ & $223(12.1)$ & $140(12.2)$ & 477 \\
\hline Almost everyday & $264(23.8)$ & $333(18.0)$ & $321(28.1)$ & 918 \\
\hline \multicolumn{5}{|c|}{ Watching television } \\
\hline Not at all & $166(15.0)$ & $511(27.6)$ & $161(14.1)$ & 838 \\
\hline Less than once in a week & $182(16.4)$ & 293(15.8) & 193(16.9) & 668 \\
\hline At least once in a week & $122(11.0)$ & $240(13.0)$ & $120(10.5)$ & 482 \\
\hline Almost everyday & $739(66.6)$ & $905(48.9)$ & $763(66.7)$ & 2407 \\
\hline
\end{tabular}

TABLE Vi Distribution OF RESPONDENTS By DEMOgRAPHic CHARACTERISTICS AND COMMUNICABLE AND NON-COMMUNICABLE DiSEASES

\begin{tabular}{|c|c|c|c|c|}
\hline \multirow{2}{*}{ Demographic Characteristics } & \multicolumn{3}{|c|}{ Communicable And Non-Communicable Diseases } & \multirow{2}{*}{ Total } \\
\hline & Diabetics & Asthma & Thyroid & \\
\hline \multicolumn{5}{|c|}{ Age group (in Years) } \\
\hline $15-29$ & $123(11.1)$ & $627(33.9)$ & $381(33.3)$ & 1131 \\
\hline $30-39$ & $331(29.8)$ & $626(33.9)$ & $399(34.9)$ & 1356 \\
\hline $40-49$ & $655(59.1)$ & $596(32.2)$ & $364(31.8)$ & 1615 \\
\hline \multicolumn{5}{|c|}{ Partner's Age (in Years) } \\
\hline Below 20 & $55(5.7)$ & $208(14.6)$ & $97(11.0)$ & 360 \\
\hline $21-30$ & $189(19.6)$ & $473(33.3)$ & $319(36.2)$ & 981 \\
\hline $31-40$ & $432(44.9)$ & $500(35.2)$ & $338(38.4)$ & 1270 \\
\hline 41 and above & $287(29.8)$ & $239(16.8)$ & $127(14.4)$ & 653 \\
\hline \multicolumn{5}{|c|}{ Marital Status } \\
\hline Never married & $36(3.2)$ & $274(14.8)$ & $213(18.6)$ & 523 \\
\hline Currently married & $962(86.7)$ & $1418(76.7)$ & $880(76.9)$ & 3260 \\
\hline Formerly married & $111(10.0)$ & $157(8.5)$ & $51(4.5)$ & 319 \\
\hline \multicolumn{5}{|c|}{ Currently Pregnant } \\
\hline No or unsure & 1098(99.0) & 1797(97.2) & $1118(97.7)$ & 4013 \\
\hline Yes & $11(1.0)$ & $52(2.8)$ & $26(2.3)$ & 89 \\
\hline \multicolumn{5}{|c|}{ Total children ever born } \\
\hline No child & $86(7.8)$ & $366(19.8)$ & $289(25.3)$ & 741 \\
\hline 2 children & $304(27.4)$ & $384(20.8)$ & $309(27.0)$ & 997 \\
\hline 3 children and above & $597(53.8)$ & $910(49.2)$ & $405(35.4)$ & 1912 \\
\hline
\end{tabular}

Table VI infers Asthma and Thyroid were common at younger ages among the respondents but when age increases the diabetics was common with higher proportion (59.1 percent) (Bjùro et al., 2000, p.642) compared to lower proportion (32.2 and 31.8 percent) with Asthma and Thyroid respectively. Respondents those who were currently pregnancy, Thyroid and Asthma were common diseases than diabetics. Similarly, the respondents had 2 children and above in their married life had experienced in higher proportion of communicable and non-communicable diseases than the respondents those who do not have a child. 
Fig. 3 reveals that Knowledge and awareness of the respondents and diseases. Those respondents who do not have reading habits of news paper at all were experienced Asthma (Six in tenth). Those who had listening radio and watching television also had less proportion of Asthma compared to other categories. This clearly indicates that those who had awareness through mass media determining the experience of diseases. Comparatively visual communications have more determination than the reading or listening on the experience of diseases among the respondents.

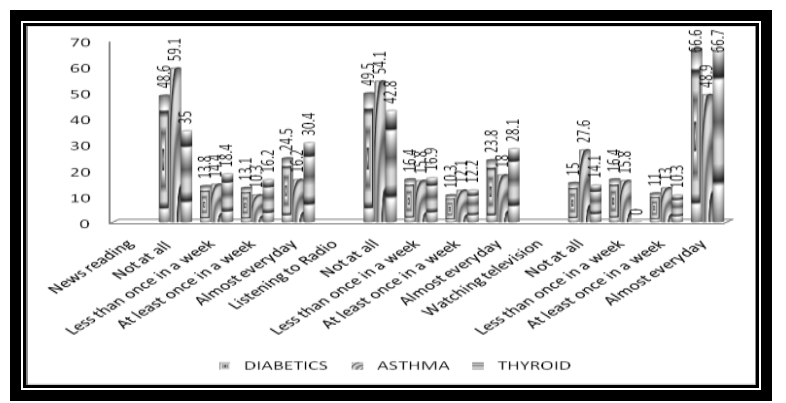

Fig. 3 Respondents by Knowledge and Communicable and Non-Communicable Diseases

TABLE VII FACTOR LOADING

\begin{tabular}{|c|l|c|l|c|}
\hline Factor & \multicolumn{1}{|c|}{ Name of the factor } & Variable number & \multicolumn{1}{|c|}{ Name of the variable } & Factor loading \\
\hline I & Personal & V103 & Age & .939 \\
\hline & & V113 & Drinking water & .786 \\
\hline & & V116 & Type of toilet & .616 \\
\hline II & Living condition & V128 & Type of wall & .710 \\
\hline & & V129 & Type of roof & .577 \\
\hline III & Social characteristics & V130 & Religion & .593 \\
\hline IV & Fuel and CEB & V201 & Cooking fuel & .768 \\
\hline & & V76EB & .661 \\
\hline V & Partner's Age and education & V106 & Partner's age & .827 \\
\hline & & V190 & Wealth index & .724 \\
\hline VI & Economic conditions & V157 & Frequency of reading news paper & .777 \\
\hline & & V160 & Toilet facility shared & .704 \\
\hline VII & Practices & V302 & Ever used any method & .775 \\
\hline & & S117 & caste & .711 \\
\hline & & V127 & Type of floor & .657 \\
\hline VIII & Status of individual & V502 & Marital status & .785 \\
\hline & & & .517 \\
\hline
\end{tabular}

TABLE VIII RotATED COMPONENT MATRIX

\begin{tabular}{|c|c|c|c|c|c|c|c|c|c|}
\hline Variable number & I & II & III & IV & V & VI & VII & VIII & Communalities \\
\hline V103 & .939 & & & & & & & & 0.927 \\
\hline V113 & .786 & & & & & & & & 0.774 \\
\hline V116 & .616 & & & & & & & & 0.589 \\
\hline V128 & & .710 & & & & & & & 0.688 \\
\hline V129 & & .577 & & & & & & & 0.539 \\
\hline V130 & & & .593 & & & & & & 0.580 \\
\hline V161 & & & & .768 & & & & & 0.654 \\
\hline V201 & & & & .661 & & & & & 0.631 \\
\hline V730 & & & & & .827 & & & & 0.742 \\
\hline V106 & & & & & .724 & & & & 0.648 \\
\hline V190 & & & & & & .777 & & & 0.737 \\
\hline V157 & & & & & & .704 & & & 0.637 \\
\hline V160 & & & & & & & .775 & & 0.756 \\
\hline V302 & & & & & & & .711 & & 0.699 \\
\hline S117 & & & & & & & .657 & & 0.638 \\
\hline V127 & & & & & & & & .785 & 0.749 \\
\hline V502 & & & & & & & & .517 & 0.492 \\
\hline Eigen values & 2.524 & 2.083 & 1.419 & 1.135 & 1.141 & 1.121 & 1.050 & 1.007 & 11.48 \\
\hline Percentage of variance & 14.008 & 9.940 & 8.602 & 8.114 & 6.268 & 5.660 & 4.774 & 4.592 & \\
\hline Cumulative percentage & 14.008 & 23.948 & 32.549 & 40.664 & 46.932 & 52.592 & 57.366 & 61.957 & \\
\hline
\end{tabular}


The results of factor analysis were very useful to determine the major dimensions of the communicable and noncommunicable diseases among the respondents. Eight dimensions were identified and contributing a total variance of 61.957 per cent. An Eigen value of 1.0 was taken as a cut-off point to determine the number of dimensions to be extracted. Correlation matrix revealed the presence of many coefficients of 0.4 and above. The Kaiser-Meyer-Oklin (KMO) value was 0.769 , exceeding the recommended value of 0.6 and the Barlett's Test of Sphericity reached statistical significance (.000), supporting the factorability of the correlation matrix. Principal components analysis revealed the presence of eight components with Eigen values exceeding 1.0

\section{A. Factor I: Personal Characteristics of the Women}

The "personal character" has been emerged as a single most vital factor with an Eigen value of 2.524 and the total variance of 14.008 percent. Three out of seventeen variables were loaded in this factor. The factor analysis has been clearly indicating that the variables namely age (0.939), source of drinking water $(0.786)$, and type of toilet $(0.616)$ were highly correlated with the communicable and noncommunicable diseases of the respondents. Thus, the respondents diseases were highly influenced and they reported that of the three diseases at the younger ages Asthma and thyroid were common among the respondents but when age increases the diabetics was common with higher proportion (59.1 percent) (Bjùro et al., 2000) compared to lower proportion (32.2 and 31.8 percent) with Asthma and Thyroid respectively.

\section{B. Factor II: Living Conditions of the Women}

The analysis of "living condition" of the respondents was found with the Eigen value of 2.083. There were two positive loading factor of the variables such as type of wall and type of roof with .710 and .577 respectively. The loading value represent the communicable and noncommunicable diseases were experienced by the respondents and their living condition either they live Natural/ Mud Plywood wall living condition, Mud/ wood/ unborn bricks roof living condition or live in stone/ finished materials, finished/ cement walls, and finished / cement roof. As the economic status improved the living condition and life style may change and so that diseases among the respondents varied.

\section{Factor III: Social Characteristics of the Women}

The factor of "social characteristics" was formed as another important factor with an Eigen value of 1.149 and the total variance was 8.602 . The positive loading factor was religion with value of. 593 .

\section{Factor IV: Fuel and Children Ever Born to a Woman}

The analysis of "Desire" of the respondents was found with the Eigen value of 1.135 . There were two positive loading factor of the variables such as cooking fuel and Total Number of children ever born (TCEB) .768 and .661 respectively. The loading value represents the communicable and non-communicable diseases were experienced by the desire of the respondents whether they would like to use smokeless materials for cooking and they would like to have more TCEB. It indicates that of the communicable and non-communicable diseases like Asthma was experienced by those who do not use LPG/Electricity. It was about 62 percent of respondents were experienced Asthma than the other two diseases (Thyroid and Diabetics).

\section{E. Factor V: Partner's Age and Education}

The "Partners' age and Education" towards the communicable and non-communicable diseases was produced with the Eigen value of 1.141. The variables that Partner's age and Level of Education had positive loading values of .827, and .724 respectively. The analysis represents those who do have no education Asthma is common diseases compared to other two diseases. But those diseases were in higher proportion among those who had the level of education was secondary and higher secondary.

\section{F. Factor VI: Economic Condition}

The "Economic Conditions" of the respondents towards the communicable and non-communicable diseases was found to be with the Eigen value of 1.121. The factor analysis has been clearly indicating that the variables namely Wealth Index (.777) frequency of reading news paper (0.939), were highly correlated with the communicable and noncommunicable diseases of the respondents. Thus, the total variance of economic conditions and communicable and non-communicable diseases was 5.660.

\section{G. Factor VII: Practices}

The factor of "Practices" of the respondents towards the communicable and non-communicable diseases was produced with the Eigen value of 1.050. The factor analysis has been clearly indicating that the variables namely toilet facility shared by the respondents (.775), ever used any method (.711) and caste (.657) was highly correlated with the communicable and non-communicable diseases. Thus, the total variance of Practices among the respondents indicates with communicable and non-communicable diseases were 4.774. It indicates that of the communicable and non-communicable diseases Asthma was experienced by 48.6 percent compared to the other two diseases such as Thyroid and diabetics among the respondents. It shows the hygiene a practice was one of the reasons for the diseases like Asthma.

\section{H. Factor VIII: Status of Individuals}

The analysis of the "Status of the individuals among the respondents towards the communicable and noncommunicable diseases was produced with the Eigen value 
of 1.007. The factor analysis has been clearly indicating that the variables namely type of floor (.785) and Marital Status (.517) was highly correlated with the communicable and non-communicable diseases. Thus, the total variance of Practices among the respondents indicates with communicable and non-communicable diseases were 4.592. About 77 percent of the respondents were experienced Diabetics as a diseases those who were living in stone/ finished materials used for the floor. It was understood from the analysis that the type of floor is sign of the status and this status leads to personal activities and ultimately affects the health of the respondents.

\section{CONCLUSION AND SUGGESTIONS}

The parts and organs communicate with each other to ensure function of the body properly. Communication among various regions of the body is essential for enabling the organism to respond appropriately to find any changes in the internal and external environments. The most common communicable and non-communicable diseases in India are common which includes Diabetics, Athma and Thyroid and their related disorders. To study of communicable and non-communicable diseases the total number of sample was 4102 from the collected sample sizes and particularly those who were answered for the above questions were taken for the analysis to find accurate information. To find the predictors of Diabetics, Asthma and Thyroid PCA was used. In connection to find the association between dependent and the predictor variables PCA was used.

The analysis part represents that of the communicable and non-communicable diseases like Asthma was experienced by those who do not use LPG/Electricity. It was about 62 percent of respondents were experienced Asthma than the other two diseases (Thyroid and Diabetics). But those diseases were in higher proportion among those who had the level of education was secondary and higher secondary. It indicates that of the communicable and non-communicable diseases Asthma was experienced by 48.6 percent compared to the other two diseases such as Thyroid and diabetics among the respondents. the respondents diseases were highly influenced and they reported that of the three diseases at the younger ages Asthma and thyroid were common among the respondents but when age increases the diabetics was common with higher proportion (59.1 percent) compared to lower proportion (32.2 and 31.8 percent) with Asthma and Thyroid respectively. It was understood from the analysis that the type of floor is sign of the status and this status leads to personal activities and ultimately affects to diabetics. The analysis represents those who do have no education Asthma is common diseases compared to other two diseases. But those diseases were in higher proportion among those who had the level of education was secondary and higher secondary.

1. Create awareness to use protected drinking water and motivate the people to use boiled water to avoid Thyroid

2. Restricted use of country fuel wood and maximum use of LPG Gas/ Electrified stoves for cooking purposes

3. Make awareness among the people to maintained clean and Green Environment

4. Government and Non Governmental organization should involve in enforcing the existing Rules and regulations.

\section{REFERENCES}

[1] Aydogdu, H., A. et al., (2008). "Indoor and outdoor airborne bacteria in child day-care centers in Edirne City (Turkey): seasonal distribution and influence of meteorological factors. Environment Monitor Assess, 8, 76-89.

[2] Bjùro et al., (2000) Prevalence of thyroid disease, thyroid dysfunction and thyroid peroxidase antibodies in a large, unselected population. The Health Study of Nord-Trùndelag (HUNT) European Journal of Endocrinology, 143, 639-647 accessed at online version via http://www.eje.org

[3] Fabian, M. P., et al., (2005). Ambient bioaerosol indices for indoor air quality assessments of flood reclamation. Aerosol Science, 36, 763-783.

[4] Joshi, M. et al., (2013). Identification of indoor airborne microorganisms in residential rural houses of Uttarakhand, India. International Journal of Current Microbiology and Applied Sciences, 2(6), 146-152.

[5] Kalpa Sharma et al., (2013) Burden of Non-Communicable Diseases in India: Setting Priority for Action. International Journal of Medical Science and Public Health, 2(1), 7-11.

[6] Kochupillai, N. (2000) Clinical endocrinology in India. Current Science, 79, 1061-1067.

[7] Lincy K. Skaria, Purnima Dey Sarkar, Gopinath Agnihotram, Amar Singh Thakur \& Girish Pamidamarri. (2011). Thyroid Dysfunctions in Tribal Women of the Bastar Region of Chattisgharh, India. Thyroid Science, 6(6), 1-5.

[8] Meena, P. (1997). Disorders of thyroid gland in India: Endocrinology, Part I. Indian Journal of Pediatrics, 64, 11-20.

[9] Upadhyay, P. R. (2011). An Overview of the Burden of NonCommunicable Diseases in India. Iranian Journal of Public Health, 41(3), 1-8. 